\title{
Effects of convective motion in n-octane pool fires in an ice cavity
}

\author{
Farahani, Harried Farmahini; Jomaas, Grunde; Rangwala, Ali S.
}

Published in:

Combustion and Flame

Link to article, DOI:

10.1016/j.combustflame.2015.09.021

Publication date:

2015

Link back to DTU Orbit

Citation (APA):

Farahani, H. F., Jomaas, G., \& Rangwala, A. S. (2015). Effects of convective motion in $n$-octane pool fires in an ice cavity. Combustion and Flame, 162(12), 4643-4648. https://doi.org/10.1016/j.combustflame.2015.09.021

\section{General rights}

Copyright and moral rights for the publications made accessible in the public portal are retained by the authors and/or other copyright owners and it is a condition of accessing publications that users recognise and abide by the legal requirements associated with these rights.

- Users may download and print one copy of any publication from the public portal for the purpose of private study or research.

- You may not further distribute the material or use it for any profit-making activity or commercial gain

- You may freely distribute the URL identifying the publication in the public portal

If you believe that this document breaches copyright please contact us providing details, and we will remove access to the work immediately and investigate your claim. 


\title{
Effects of convective motion in n-Octane pool fires in an ice cavity
}

\author{
Hamed Farmahini Farahani ${ }^{\mathrm{a}^{*}}$, Grunde Jomaas ${ }^{\mathrm{b}}$, Ali S. Rangwala ${ }^{\mathrm{a}}$ \\ a Department of Fire Protection Engineering, Worcester Polytechnic Institute, Worcester, MA \\ 01609, USA \\ b Technical University of Denmark (DTU), Department of Civil Engineering Brovej, Building \\ 118 DK-2800 Kgs. Lyngby, Denmark \\ *Corresponding Author: \\ Hamed Farmahini Farahani \\ 100 Institute Road, Worcester, MA 01609 USA
}

Phone: 1-508-831-5027

Fax: 1-508-831-5862

E-mail: ffarahani.hamed@gmail.com

Type of Article:

Full Length Article

\begin{abstract}
The effects of convective flows in n-Octane pool fires in an ice cavity were investigated and it was found that a new set of parameters to the classical problem of bounded pool fires arises under these unique conditions. To systematically understand these parameters, two sets of experiments were performed by burning n-Octane in cylindrical shape ice cavities of $5.7 \mathrm{~cm}$ diameter. The first set of experiments was intended to provide a clear understanding on the geometry change of the cavity and displacement of the fuel layer. The results of these experiments showed the rate of melting the ice walls were higher in areas the fuel layer was in contact with ice compared with places where the flame was present. Because of melting of the ice walls a ring shaped void was formed around the perimeter of the cavity. Also, it was found that the melting rate was greater in the second half of the burning period. In the second set of
\end{abstract}


experiments, the change in the temperature of the fuel layer was measured by use of multiple thermocouples at different locations inside the ice cavity. The results of the temperature analysis showed that the lateral temperature gradient of the fuel layer was an increasing function of time while vertical temperature gradient was a decreasing function. Using the experimental results, two dimensionless numbers (Marangoni and Rayleigh) were calculated that represent surface tension driven and buoyancy driven flows in the fuel layer, respectively. The results of this study showed two major convective phases. In the first half of the burning time, buoyancy driven flows were dominant, while Marangoni convection was dominant in the second half of the burning time. The role of these mechanisms in affecting the flow and melting the ice is discussed.

Keywords: convective flow, octane, pool fire, ice, Arctic

\section{Introduction}

The study of flow within liquid fuels and pool fires in general has been of interest both from fire safety concerns and from a scientific point of view. The phenomenology and understanding the controlling mechanisms of liquid flow in pool fires have aided fire researchers in recommending methods to lessen the risks associated with use of liquid fuels. Liquid-phase convection in pool fires was the subject of investigation in the 1955-1980 research period, and particularly two topics of interest, ignition and flame spread, were studied extensively and their association with the motion in liquid fuels were acknowledged [1, 2]. Specifically, it was shown that the rate of flame spread in liquid fuels with an initial temperature below the fuel's flash point temperature is governed by liquid-phase convection [3]. The liquid fuel flow pattern was first documented by Burgoyne et. al. [4] during experiments of flame spread over alcohol pools. They attributed the motion in the liquid to buoyancy effects. Later, studies revealed that both surface tension and buoyancy were the driving forces in the flame spread of the liquids fuels and they predicted the surface tension to be dominant [5-7]. It was found that the liquid-phase convection in flame spread is driven initially by surface tension (Marangoni or thermo-capillary flow) then by

buoyancy forces and, to a much lesser degree, by evaporation and thermal expansion [8]. However, further studies revealed the significant role of surface tension driven flows during the flame spread process [9-11]. Although there has been an extensive work on convective flow in the flame spread process, only a few studies have addressed the transport phenomena throughout the burning of pool fires [12-14]. 
In a typical pool fire (contained with sidewalls), a portion of the heat produced by the flame transfers to the body of liquid fuel in deeper areas through the rim of the pan, and thereby creating local convective flows [15]. When the rigid walls of the pan are replaced with walls of ice, the transport mechanisms are significantly altered. Such a situation will arise for example during clean-up of oil spills in the Arctic using the in-situ burning method [16]. In two previous studies on burning of liquid fuels in ice cavities, a phenomenon was observed which is referred as “lateral cavity formation”. During burning of liquid fuels in ice cavities [17] and ice channels [18] (where the fuel was surrounded by walls of ice) the burning fuel was observed to penetrate radially into the ice. The size of the lateral cavity formed on the circumference of the original cavity by the fuel layer was found to vary with fuel type, and different geometric configurations of ice.

From a practical point of view there are some disadvantages to these deformations. For example, such a deformation will allow a portion of the oil to drift underneath the lateral cavity. This is presumed to be a potential factor in reducing the burning efficiencies by preventing the exposure of air to the trapped oil. A decrease in the burning efficiency means a larger amount of oil residue. In addition, the confined residue in the cavity would be harder to collect and increase the cost of the post-burn clean-up during in-situ burning operations. In particular, if the residue stays untreated, it could be encapsulated due to freezing of the water in colder seasons and potentially remain in the ecosystem for years.

The hypothesis to explain the formation of lateral cavities is that the penetration in ice is caused by flows in the liquid fuel layer. The observations made during experiments of this study corroborate existence of a flow close to the free surface of the fuel. The driving forces behind the flow in liquid fuel are anticipated to be buoyancy and surface tension, relating to natural and Marangoni convection, respectively. However, the relative contribution of each of these mechanisms needs to be studied. Therefore, it is required to find out the influence of these convective flows within the fuel layer to understand formation of lateral cavities in the ice walls.

The objectives of this study are to understand the convective motions in the fuel layer (role of thermocapillary and natural convection) and to relate these to the lateral cavity formations during in-situ burning of liquid fuels in ice cavities. It is envisioned that the results of this study could give a solution toward higher efficiency of in-situ burnings in Arctic condition. 


\section{Experimental Procedure}

Figure 1 shows the experimental setup with n-Octane in a $5.7 \mathrm{~cm}$ diameter ice cavity. Each experiment used an ice block with a circular cavity excavated in its center. The depth $(H)$ and initial fuel layer $(L)$ were chosen based on the data obtained from preliminary tests to prevent overflow and spillage during burning n-Octane. The ice block was placed on a drip pan on top of a load cell (precision of $0.01 \mathrm{~g}$ ) to record mass loss of the fuel. Then, $30 \pm 0.1 \mathrm{~g}$ n-Octane was added to the cavity (with no water base-layer) and a propane torch igniter was used to ignite the fuel layer immediately after n-Octane was poured into the cavity.

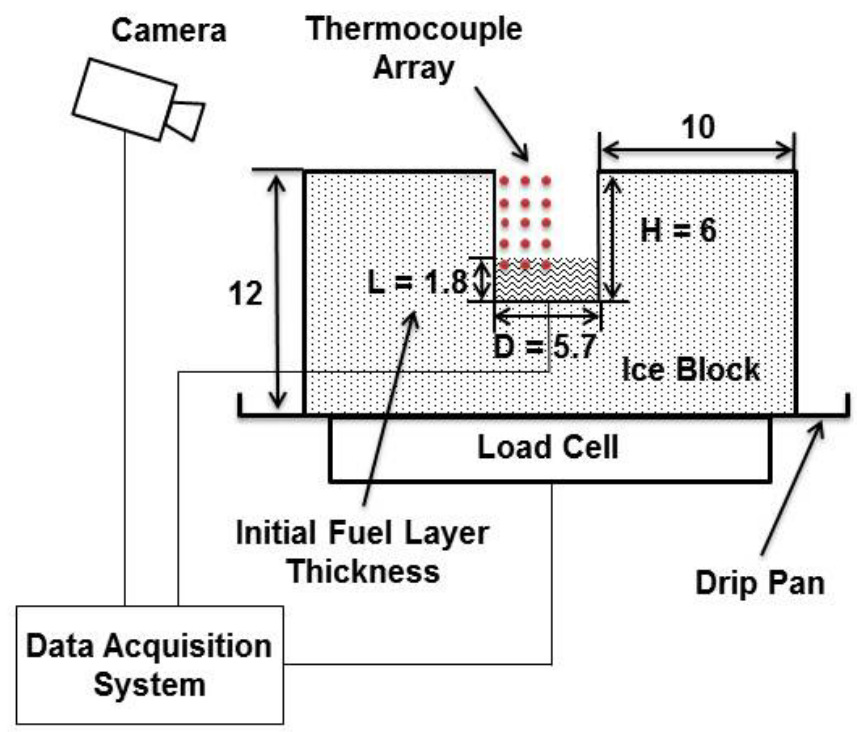

Figure 1. Schematic of the experimental setup. The dimensions are in $\mathrm{cm}$ with an uncertainty of $\pm 0.05 \mathrm{~cm}$ for $D$ and $\pm 0.1 \mathrm{~cm}$ for $H$.

Two sets of experiments were performed to collect data for analysis. In the first set, ten identical tests were conducted where the only varying parameter was the burning duration. In the first experiment n-Octane was allowed to burn only for 1 minute and then it was extinguished. The second experiment was extinguished after 2 minutes and so on. After each test the ice blocks were cut in half and a photograph was taken from the cross section. In addition, measurement of ice cavity geometry was made by processing the images. These tests were intended to give an understanding of the process of geometrical changes of the ice and lateral cavity formation. In addition, the free surface of the fuel was tracked visually by the camera which was positioned on top of the ice block and the interface of the fuel-water was calculated based on the fuel layer thickness at each time stamp. The fuel layer thickness was also calculated based on the diameter of cavity and remaining mass of the fuel (Load cell data). In the second set, experiments were 
conducted with 3 thermocouples (type $\mathrm{K}$, gauge 36, and $0.13 \mathrm{~mm}$ diameter protected by ceramic tubes with a 1-2 mm exposed junction) placed inside the cavity as shown with solid circles in Fig. 1. These tests were repeated 5 times with the thermocouple (TC) array placed at different elevations in the cavity to create a temperature map of the liquid fuel within the cavity. A more detailed description of the TC implementation is given in Section 3.2.

\section{Results and Analysis}

Measurements of mass loss over time as well as the images taken from the cavity were used to measure and analyze the geometry change of the cavity and thickness of the fuel layer. The results are reported in Section 3.1. along with a discussion on lateral cavity formation. The temperature profile of the fuel layer was obtained by using different arrangements of TCs inside the cavity and within the fuel layer. The results of the temperature analyses are reported in Section 3.2. A discussion on convective flow within the fuel layer and the effects of the fuel layer on melting of the ice follows in Section 3.3.

\subsection{Cavity Change}

The geometry change of the original cavity in ice during combustion of liquid fuels has been reported to be an important reason in affecting the burning rate and efficiency of a liquid fuel [17]. However, the exact changeover of the cavity into its final shape and formation of lateral cavity has not been discussed in earlier studies $[17,18]$. In order to provide a detailed observation of the geometry change of the ice cavity, 10 experiments with similar initial condition were performed as explained in Section 2. Figure 2 shows the change in cavity geometry with few of the corresponding dimensions labeled in the figure. 

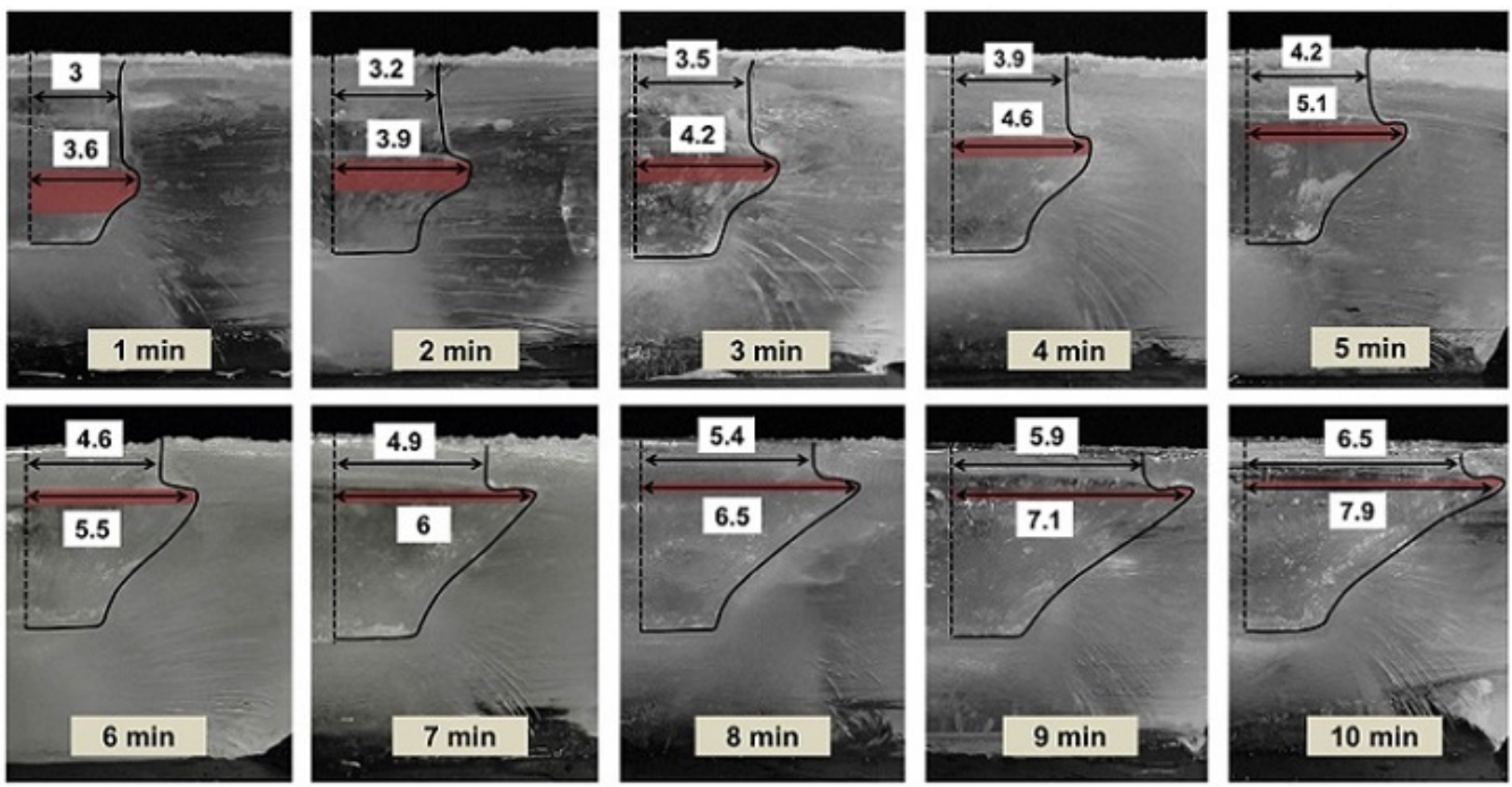

Figure 2. Lateral cavity formation in sequential steps from top left in photos of ice blocks cut in half after the experiment. The dashed line represents the centerline of the cavity. The dimensions are in $\mathbf{c m}$.

As shown in Fig. 2, at any instance during burning the n-Octane pool, the ice walls of the cavity were melting and the diameter of the cavity was constantly increasing. However, it was observed that the rate of melting of the ice walls were higher in areas the fuel layer was in contact with ice compared with places where the flame was present. The melted ice created a semi-hemisphere void inside and around the circumference of the cavity. Thus, a lateral penetration of the fuel layer was observed around the perimeter of the original cavity. The final diameter of the cavity measured at the location of the fuel layer $(D)$ was $15.8 \mathrm{~cm}$ where the diameter at the top surface of ice $\left(D^{\prime}\right)$ was $13 \mathrm{~cm}$. This translates into a partial penetration length (defined as $\frac{D-D^{\prime}}{2}$ ) of roughly $1.4 \mathrm{~cm}$ for a 10 minute burning period. Note the total penetration (calculated from original position of the ice wall) of the fuel layer was larger (about $5 \mathrm{~cm}$ ). With this estimation the area of the fuel layer would be roughly $30 \%$ larger than the cavity opening area which means difficult air entrainment for a portion of the fuel. Thus, the burning rate of the fuel would be lower.

As mentioned, during burning the n-Octane pool, the penetration length into the ice wall was observed to be larger wherever the liquid fuel was in contact with ice. Contrary to the intuitive 
assumption that the flame's leading edge (temperature range of $1000-1300{ }^{\circ} \mathrm{C}$ ) can melt the ice faster, it became evident that the liquid fuel (temperature range of $80-125^{\circ} \mathrm{C}$ ) is melting the ice at a much faster pace. Melting is an endothermic process and it requires a significant portion of the produced heat by combustion of the fuel to be consumed. This suggests existence of a great heat transfer coefficient in the liquid phase compared with that of the gas phase [19].

In burning of the fuels in an ice cavity, a portion of the released heat by the burning of the fuel is transferred to the walls thus converting the ice to water. Because of higher density of water (compared with that of the fuel) a layer of water forms at the base of ice cavity forcing the fuel layer to elevate with respect to the bottom of the cavity [18]. For these experiments, the change in the thickness of the fuel layer (because of expansion of the cavity and evaporation of the fuel) and position of the fuel layer at each time stamps are shown in Fig. 3.

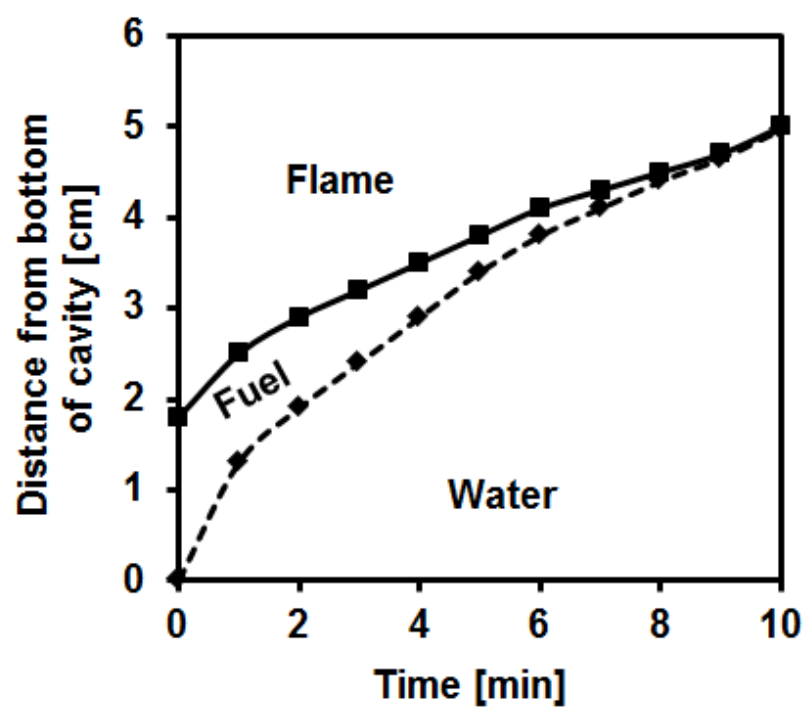

Figure 3. Elevation of the fuel layer in cavity (free surface and water-fuel interface shown in solid and dashed line, respectively). The time in the figure is the time after ignition.

As illustrated in Fig. 3 the thickness of the fuel layer was initially at $1.8 \mathrm{~cm}$ (equal to $\sim 30 \mathrm{~g}$ of nOctane) and reduced to $\sim 0$ at the end of the burning. The evaporation of the liquid fuel because of burning and the increase in the diameter of cavity are the two main reasons for the fast regression of the fuel layer thickness. It should be noted that in the final stage of burning (last 3 minutes) the fuel layer accumulated in a ring shape around the perimeter of the cavity. This ring shrunk and became slimmer as more fuel evaporated but maintained a $2 \mathrm{~mm}$ thickness which is required for continuous burning [20]. Because of accumulation of water at the base of the cavity, 
the fuel layer elevated relative to the volume of the melt water. In a $5.7 \mathrm{~cm}$ diameter ice cavity, combustion of $30 \mathrm{~g}$ n-Octane resulted in melting of $350 \mathrm{~g}$ ice. This amount of melted water makes a significant increase in a fairly small cavity. However, for large cavity diameters the elevation of the fuel layer is expected to be insignificant.

\subsection{Temperature History}

As part of this study, the temperature distribution of the fuel layer was measured by thermocouples (TCs). The initial fuel layer was $1.8 \mathrm{~cm}$ as shown in Fig. 4. But through evaporation and geometry change of the ice cavity it became as thin as about $2 \mathrm{~mm}$ during the final stage of burning. As shown in Fig. 4, the $2 \mathrm{~mm}$ fuel layer remained only near the perimeter of the cavity and formed a ring shape slick. The thermocouple array setup is also shown in Fig. 4. The TC array consisted of 3 parallel ceramic tubes enclosing the TC wires each $1 \mathrm{~cm}$ apart horizontally. Insulated thermocouple wires were passed through the ceramic tubes for protection against flame and liquid fuel. The opening of the tube (immersed in liquid) was also blocked by heat resistant cement to prevent fuel from entering into the ceramic tube. Thus, the only exposed parts of the TCs were the 1-2 mm Junctions. A holder was used to position the 3 TC beads at fixed elevations for each test. A total number of 5 tests were performed with TC array being at different elevations (each $1 \mathrm{~cm}$ apart) with respect to the bottom of the cavity for test 1 through test 5. Thermocouple measurements were used to create a temperature map of the liquid fuel as it rose up within the cavity. The corresponding location of TCs for each test is shown in Fig. 4. The uncertainty for the location of the TC array was $0.1 \mathrm{~cm}$.

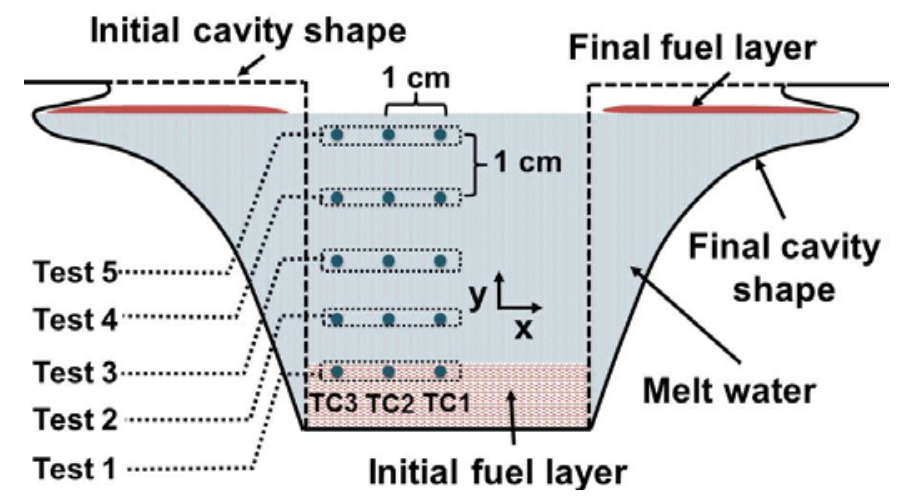

Figure 4. Thermocouple array setup used to obtain the temperature history of the liquid fuel.

The three TCs positioned at different locations along the x-direction (TC1 being at the center of cavity and TC3 near the ice wall, as shown in Fig. 4) recorded the temperature of gas phase and 
because melting of ice caused the fuel layer to rise, it eventually recorded the temperature of $n$ Octane surface and that of water. The elevation of the liquid layer caused a sudden drop in the temperature recorded by these TCs. This moment was defined as the instant that the TCs immerse into the liquid fuel (500-700 ${ }^{\circ} \mathrm{C}$ drop in temperature readings). Considering the boiling point of n-Octane is $125^{\circ} \mathrm{C}$, the temperature measurements in a 5 seconds period after this moment were averaged. This averaged value was assumed to be the instantaneous surface temperature of the fuel. As expected, the temperature of the fuel layer free surface measured at center line of the cavity had the greatest value compared with the other locations measured. This is due the higher input radiation from the flame in the center [21]. Based on the findings of Hamins et al. [22], there should be a constant decrease of local heat feedback outward from the center and then a rise near the rims because of local heating of the fuel by the heat conducted through the rims to the body of the fuel. In a pool fire in ice the component of heat transfer of the flame through rims to the body of the fuel does not exist. Still, the temperature readings at location of TC3 are higher than that of TC2. The explanation for this difference would be the existence of a high local burning rate near the perimeter of the ice cavity [23].

Using the temperature data, temperature gradient of the fuel layer along vertical and lateral directions were obtained. In Fig. 5(a) the horizontal temperature gradient $\left(\Delta T_{h}\right)$ on the fuel surface is shown for the distances between the TCs and the ice wall. The assumption was that temperature of n-Octane adjacent to the ice wall is similar to that of ice $\left(0^{\circ} \mathrm{C}\right)$. Except for the first data point (25 s after ignition) the $\Delta T_{h}$ trend shows a monotonic increase. This initial nonlinearity may be due to the effect of ignition by the propane torch. The vertical temperature gradient $\left(\Delta T_{v}\right)$ was also specified as the temperature difference between the free surface of the fuel and fuel-water interface. Figure 5(b) shows the vertical temperature difference of n-Octane. As expected, the $\Delta T_{v}$ of the fuel layer was initially high and plummeted to small values toward the end of the burning. The decline in the fuel layer thickness increased the in-depth heat transfer, and resulted in higher temperature at the fuel-water interface. 


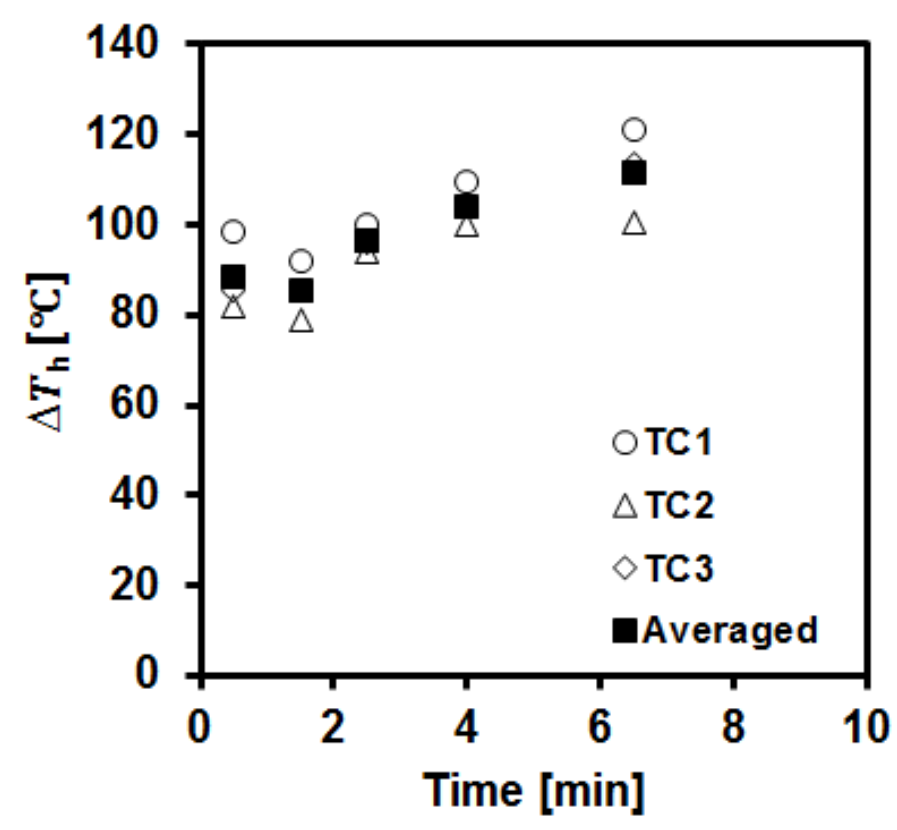

(a)

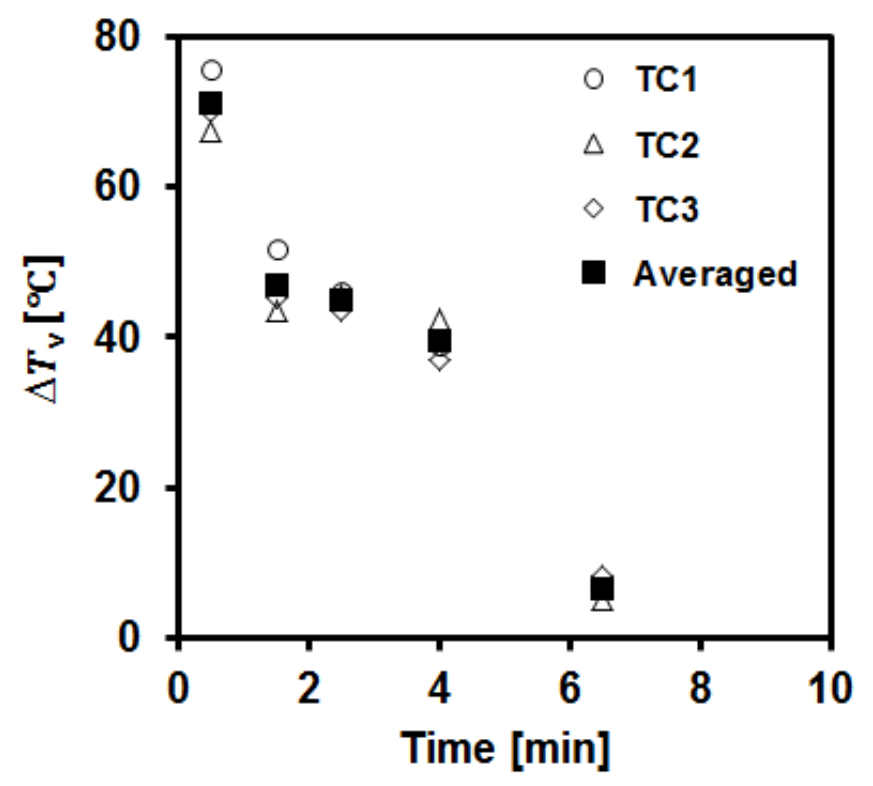

(b)

Figure 5: Temperature gradient of fuel layer in horizontal (a) and vertical (b) axes.

\subsection{Discussion on convective flows in the liquid fuel}

The melting of the ice alongside the n-Octane pool was assumed to be associated with the dynamic heat and mass transfer in the fuel layer. Thus far, the convective flows in the liquid phase of pool fires in an ice cavity have not been studied. Therefore, it is important to analyze 
the convective flows in these situations opposed to the convective flows in the classical bounded pool fires problem. In typical pool fires, the convective motion in liquid fuels had been attributed mostly to buoyancy driven flows (occurring near the rims of the pan) and to surface tension driven flows. Normally, the flow in the liquid fuel is retarded by the convective motion related to the Rayleigh number and is enhanced by the convective motion related to the Marangoni number. Though, when the liquid fuel is bounded by ice (instead of rigid walls) the mechanisms inducing the convective motions alter significantly. In areas closer to the ice a downward flow is expected to occur because of severe low temperature of the ice. In addition, because of presence of the ice a horizontal temperature gradient exists along the surface of the fuel which produces surface tension variation on the surface of the fuel. Surface tension is a decreasing function of temperature for most of the liquids at most temperatures. Therefore, for a liquid of non-uniform surface temperature, variation of surface tension drives a flow in liquid. This phenomenon is known as Marangoni or thermo-capillary convection [24].

In this study, the temperature of the fuel surface in centerline of the pool is about $125{ }^{\circ} \mathrm{C}$ and decreases to $0{ }^{\circ} \mathrm{C}$ directly at the side of the ice walls. Therefore, a surface tension driven flow should arise toward the ice wall outward from the center (Thermo-capillary convection) and downward in the liquid adjacent to the wall (Natural convection). The coupling between the buoyancy driven and surface tension driven flows creates a significant transport of mass and heat which provides the necessary heat to melt the ice. The relative contributions of these mechanisms are shown and discussed further in this section.

In addition, the pattern of flow is of an intriguing nature. The pattern of flow and vortices formed in the liquid fuel burning of contained pool fires are reported to include two groups of vortices. A main counter rotating vortex in the center of pool (characterized by a larger radii and higher velocities) and a vortex closed to the rims of vessel formed due to buoyancy [12, 13]. The exact flow pattern of the burning liquid fuel in this study remains unstudied. However, by the observations made during this study it is likely to see vortices with large radii near the free surface of the fuel. Figure 6 is showing the conceptual paths of the flow for the two cases. These vortices are expected to enhance in velocity during the second half of burning where the fuel layer has become thin. 


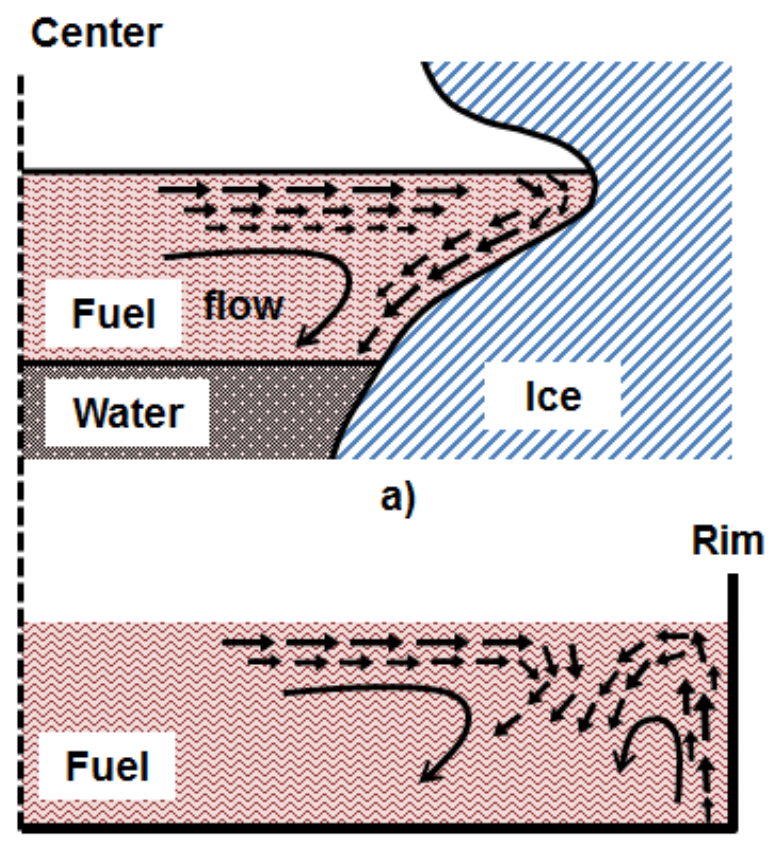

b)

Figure 6. Conceptual sketch showing the paths of the flow within the fuel layer for a) contained pool fires, b) pool fires in ice cavity.

The observation made during experiments showed soot particles to be traveling on the fuel surface away from center toward the ice wall. Figure 7 displays one rather large particle captured on camera. This particle traveled a length of $1.5 \mathrm{~cm}$ in 1.28 seconds which is equal to traversing the final diameter of cavity $(\sim 16 \mathrm{~cm})$ about 50 times in the 10 minutes burning period. This motion should not be mistaken with surface standing waves which are associated with the gas phase pulsation exerting perturbation on liquid surface [22]. 


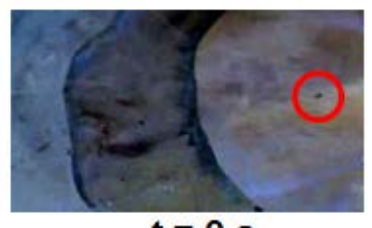

$\mathrm{t}=0 \mathrm{~s}$

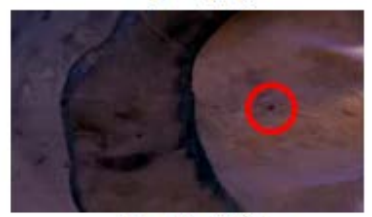

$\mathrm{t}=0.48 \mathrm{~s}$

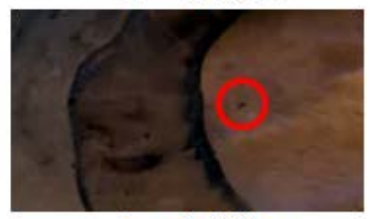

$t=0.88 \mathrm{~s}$

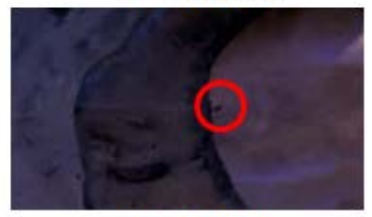

$t=1.28 \mathrm{~s}$

Figure 7. Movement of a soot particle on the surface of the fuel. The particle travels a length of $1.5 \mathrm{~cm}$ in 1.28 seconds towards the ice wall. Solid ice, ice cavity, and fuel surface from left to right.

To analyze the proportionality of the driving forces in the liquid fuel, Marangoni and Rayleigh numbers have been used as the relevant dimensionless groups for thermocapillary and natural convection, respectively [12]. The effect of evaporation on the fluid flow was assumed to be negligible so only surface tension and buoyancy have been considered as driving forces for fluid motion [10, 11, 25-27]. These dimensionless numbers can be represented as:

$$
\begin{aligned}
& M a=\frac{\sigma_{T} R \Delta T_{h}}{\mu \alpha} \\
& R a=\frac{\beta g L^{3} \Delta T_{v}}{\vartheta \alpha}
\end{aligned}
$$

Where, $\sigma_{T}=\frac{\partial \sigma}{\partial T}$ is the change of surface tension per ${ }^{\circ} \mathrm{C}, R$ is the radius of the cavity, $L$ is the thickness of the fuel, $g$ is the acceleration due to gravity, and $\beta, \mu$, $\vartheta$, and $\alpha$ are thermal expansion, viscosity, kinematic viscosity and thermal diffusivity of the liquid, respectively. The physical properties of the n-Octane were acquired by using a commercial software (Aspen HYSYS) and the change of surface tension was calculated for the temperature range of 80-125 
${ }^{\circ} \mathrm{C}$. The dimensions ( $R$ and $\left.L\right)$ and also the temperature differences $\left(\Delta T_{h}\right.$ and $\left.\Delta T_{v}\right)$ were obtained experimentally as explained in section 3.1 and 3.2.

After collecting all the relevant variables, $M a$ and $R a$ numbers can be calculated. Figure 8 shows the ratio of $M a$ to $R a$ calculated for the first 7 minutes of burning. Because of the severe reduction of thickness of the fuel layer and $\Delta T_{v}$ during the course of combustion the Rayleigh number reduces within orders of magnitude. On the contrary, radius of the cavity and $\Delta T_{h}$ are increasing function of the time, hence Marangoni number increases by 4 times. Consequently, $\mathrm{Ma} / \mathrm{Ra}$ ratio increases from very small values to unity and larger after about 5-6 minutes. Two major convective phases could be assigned to the fuel layer based on this ratio. The first phase would be the first 6 minutes of burning where buoyancy driven forces are dominant and the second phase occurs during the rest of burning time where Marangoni convection is dominant.

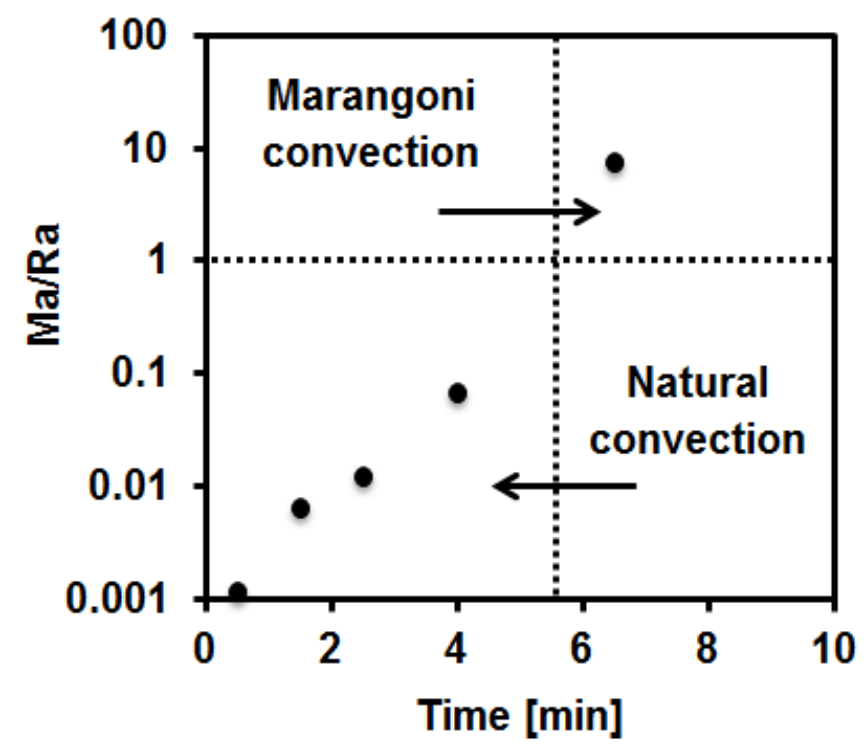

Figure 8. The ratio of Marangoni to Rayleigh number. On the abscissa, 0 indicates the ignition time and $\mathbf{1 0}$ is the time for extinction of the flame.

The results of the analysis showed dominance of natural convection in the first half of the burning period when the fuel layer was considerably thick (1.8-0.5 cm). However, Marangoni convection overcame in the final half of the burning. The corresponding total penetration lengths of the fuel layer in ice for the first and second half of the burning were 2.1 and $2.8 \mathrm{~cm}$, respectively. Also, the partial penetration lengths for the first and second half of the burning were 0.9 and $1.4 \mathrm{~cm}$, respectively. It is agreed that a large amount of the produced heat should be transferred to the ice through the fuel layer to melt the ice. In view of that, the heat transfer rate 
to the ice is obviously higher during the second phase which means the Marangoni convection could actually play a bigger role in melting the ice.

The two driving mechanisms (buoyancy and surface tension variation) inducing the convective flow in the liquid were analyzed to understand their contribution to the melting process. Usually, pressure, viscous, inertial and surface tension forces are of secondary importance and buoyancy alone is the dominating force for flow in liquid. Hence, it is uncommon for Marangoni force, under normal gravitational condition and for a macroscopic scale, to overcome the buoyancy effect [28, 29]. Yet, because of the particular circumstances involved in burning of a liquid fuel adjacent to ice such occurrence is observed.

\section{Conclusions}

A series of experiments were conducted to develop an understanding on the geometry change of an ice cavity during burning of n-Octane. Based on the observations made during the experiments it became evident that the fuel layer is capable of melting the ice at a faster pace compared with the flame. Thus, a void is shaped in the circumference of the ice wall which is called lateral cavity. Temperature measurements of the fuel layer obtained during the burning of n-Octane show a temperature gradient both in vertical and horizontal axes. This gradient contributed to creating convective motion in the liquid fuel. The driving forces inducing the convective motion were assumed to be surface tension and buoyancy. The Marangoni and the Rayleigh numbers were calculated as the relevant dimensionless numbers for surface tension and buoyancy, respectively. The results of the analysis showed dominance of natural convection in the first half of the burning period when the fuel layer is considerably thick $(1.8-0.5 \mathrm{~cm})$. However, Marangoni convection seems to overcome in the final half of the burning. The corresponding total penetration lengths of the fuel layer in ice for the first and second half of the burning were 2.1 and $2.8 \mathrm{~cm}$, respectively. A flow visualization study on this subject is required to comprehend the pattern of flow and shape of vortices in the liquid fuel.

\section{Acknowledgement}

This study was funded by the Bureau of Safety and Environmental Enforcement, US Department of the Interior, Washington, DC, under Contract Number E14PC00010. Hamed Farmahini Farahani and Grunde Jomaas were supported by a grant from the Danish Science Foundation. The contents do not necessarily reflect the views and policies of the BSEE, nor does mention of 
the trade names or commercial products constitute endorsement or recommendation for use.

\section{References}

[1] H.D Ross, Ignition of and Flame Spread Over Laboratory-Scale Pools of Pure Liquid Fuels, Prog. Energy Combust. Sci. 20 (1994) 17-63

[2] F. J. Miller, H. D. Ross, Further observations of flame spread over laboratory-scale alcohol pools, Symposium (International) on Combustion, (1992), 1703-1711.

[3] R. Mackinven, J. Hansel, I. Glassman, Influence of laboratory parameters on flame spread across liquid fuels, Combustion Science and Technology 1 (1970) 293-306

[4] J. Burgoyne, A. Roberts, P. Quinton, The spread of flame across a liquid surface. I. The induction period, Proceedings of the Royal Society of London. Series A. Mathematical and Physical Sciences 308 (1968) 39-53

[5] I. Glassman, J.G Hansel, Fire Research Abstracts and Reviews 10 (1968) 217-234

[6] K.E Torrance, Comb. Sci. Tech. 3 (1971) 133

[7] I. Glassman, F. Dryer, Flame Spreading Across Liquid Fuels, Fire Safety Journal 3 $(1980 / 81) 123-138$

[8] R. Murad, J. Lamendola, H. Isoda, M. Summerfield, A Study of Some Factors Influencing the Ignition of a Liquid Fuel Pool Combustion and Flame 1 (1970) 289-298

[9] D.N Schiller, "Combustion above liquid fuel pools: Buoyant and surface tension-driven flow computations," Ph.D., Irvine, CA, 1991.

[10] D.N Schiller, W.A Sirignano, Buoyant- Thermocapillary flow with nonuniform supra heating: II. Twho phase behavior, J. Thermophysics 6 (1992) 113-120

[11] D.N Schiller, W.A Sirignano, Buoyant-Thermocapillary Flow with Nommiform SupraHeating: I. Liquid-Phase Behavior, J. Thermophysics 6 (1992) 105-112

[12] T. YUMOTO, A. TAKAHASHI, T. HANDA, Combustion Behavior of Liquid Fuel in a Small Vessel: Effect of Convective Motion in the Liquid on Burning Rate of Hexane in the Early Stage of Combustion, COMBUSTION AND FLAME 30 (1997) 33-43

[13] A. Vali, D. S. Nobes, L. W. Kostiuk, Transport phenomena within the liquid phase of a laboratory-scale circular methanol pool fire, Combustion and Flame 161 (2014) 1076-1084

[14] F. J. Higuera, Steady thermocapillry-Buoyant flow in an unbounded liquid layer heated nonuniformly from above, Physics of Fluids 12 (2000) 2186-2197

[15] A. Nakakuki, Heat Transfer Mechanisms in Liquid Pool Fires, Fire Safety Journal 13 (1994) 339-363

[16] N. K. Smith and A. Diaz, In-place Burning of Crude Oil in Broken Ice- 1985 Testing at OHMSETT, in Arctic and Marine Oilspill Program, (1985.

[17] H. F. Farahani, X. Shi, A. Simeoni, A. S. Rangwala, A study on burning of crude oil in ice cavities, Proc. Combust. Inst. 35 (2014) 2699-2706

[18] P. W. Bellino, A.S. Rangwala, M.R. Flynn, A study of in situ burning of crude oil in an ice channel, Proc. Combust. Inst. 34 (2013) 2539-2546

[19] R. Hosseini, M. Rahaeifard, Experimental investigation and theoretical modeling of icemelting processes, Experimental Heat Transfer 22 (2009) 144-162

[20] N. K. Smith, A. Diaz, In-place Burning of Prudhoe Bay Oil in Broken Ice, Proceedings of the 1985 Oil Spill Conference, (1985.

[21] D. Drysdale, An Introduction to Fire Dynamics, 3rd ed.: John Wiley \& Sons Ltd, 2011.

[22] A. Hamins, S. Fischer, T. Kashiwagi, Heat Feedback to the Fuel Surface in Pool Fires, Combustion Science and Technology 97 (1994) 37-62

[23] A. Nakakuki, Heat Transfer in Small Scale Pool Fires, Combustion and Flame 96 (1994) 311-324 
[24] K. Sefiane, C. A. Ward, Recent advances on thermocapillary flows and interfacial conditions during the evaporation of liquids, Advances in colloid and interface science 134 (2007) 201-223

[25] N. Zhang, Surface tension-driven convection flow in evaporating liquid layers, Surface Tension-driven Flows and Applications, Research Signpost (2006)

[26] B. M. Carpenter, G. Homsy, Combined buoyant-thermocapillary flow in a cavity, Journal of Fluid Mechanics 207 (1989) 121-132

[27] T. Doi, J. N. Koster, Thermocapillary convection in two immiscible liquid layers with free surface, Physics of Fluids A: Fluid Dynamics (1989-1993) 5 (1993) 1914-1927

[28] S. Ostrach, Low-gravity fluid flows, Annual Review of Fluid Mechanics 14 (1982) 313345

[29] J. Straub, The role of surface tension for two-phase heat and mass transfer in the absence of gravity, Experimental Thermal and Fluid Science 9 (1994) 253-273 